\title{
Collagen Synthesis, Nitric Oxide and Asymmetric Dimethylarginine in Diabetic Subjects Undergoing Hyperbaric Oxygen Therapy
}

\author{
F. GURDOL ${ }^{1}$, M. CIMSIT ${ }^{2}$, Y. ONER-IYIDOGAN ${ }^{3}$, H. KOCAK ${ }^{4}$, S. SENGUN $^{2}$, \\ S. YALCINKAYA-DEMIRSOZ ${ }^{1}$
}

${ }^{1}$ Department of Biochemistry, and ${ }^{2}$ Department of Underwater and Hyperbaric Medicine, Istanbul Faculty of Medicine, Istanbul University, Çapa, Istanbul, Turkey, ${ }^{3}$ Medical Services Training School, Medical Laboratory Program, Istanbul University, Cerrahpaşa, Istanbul, Turkey, ${ }^{4}$ Istanbul Bilim University, Faculty of Medicine, Department of Biochemistry, Esentepe, Istanbul, Turkey

Received October 22, 2008

Accepted June 3, 2009

On-line August 12, 2009

\section{Summary}

The main pathological condition in patients with impaired wound healing is diabetes mellitus. These patients have significantly low circulating nitric oxide (NO) levels because the stimulatory action of insulin on NO synthesis is absent. Additionally, asymmetric dimethylarginine (ADMA), an inhibitor of NO synthase, is increased owing to the generation of oxidative stress. NO was thought to contribute to wound healing. Hyperbaric oxygen (HBO) treatment is generally used in order to accelerate the healing of wounds. The aim of this study was to determine the changes in plasma procollagen type I and III N-terminal peptides (PINP and PIIINP), total nitrite/nitrate (NOx) and ADMA levels; and to evaluate their relation to healing during the $\mathrm{HBO}$ treatment of foot ulcers. Data obtained from 18 diabetic patients before and after the HBO therapy were compared statistically by the Wilcoxon test. NOx was increased in 11 and ADMA was decreased in 12 patients following HBO treatment. Both PINP $(32.6 \pm 29.4 \mu \mathrm{g} / \mathrm{l} v s 44.3 \pm 33.4 \mu \mathrm{g} / \mathrm{l})$ and PIIINP $(6.97 \pm 3.01 \mu \mathrm{g} / \mathrm{l}$ vs $7.92 \pm 2.49 \mu \mathrm{g} / \mathrm{l})$ were significantly increased $(\mathrm{p}<0.05)$. Progressive reductions were observed in wound areas, as assessed by the digital wound imaging. In 12 patients, wounds healed by $50 \%$ or higher; whereas only two subjects had minimal improvements ( $15 \%$ or less healing). The duration of diabetes correlated negatively with wound healing $(r=-498$, $\mathrm{p}<0.05$ ). This study suggests that increased collagen synthesis is associated with wound healing during hyperbaric oxygen therapy. Nitric oxide generation may also contribute to the healing process.

\author{
Key words \\ Hyperbaric oxygen • Collagen • Nitric oxide • Asymmetric \\ dimethylarginine $\bullet$ Diabetic foot
}

\section{Corresponding author}

Figen Gürdöl, Department of Biochemistry, Istanbul Faculty of Medicine, Capa, 34093, Istanbul, Turkey. E-mail: figur@istanbul.edu.tr

\section{Introduction}

Wound healing is a complex process, involving inflammation, fibroplasia, neovascularization, collagen deposition, epithelialization and wound contraction. Collagen synthesis in wounds has been documented by increased concentrations of fibroblasts, presence of type I collagen mRNA, increased production of growth factors, and decreased activity of the matrix metalloproteinases (Sheikh et al. 2000, Kang et al. 2004). On the other hand, elevated expression of extracellular matrix metalloproteinases, decreased proliferation rate of fibroblasts and decreased expression of growth factors have been demonstrated in non-healing chronic wounds (Hehenberger et al. 1998, Cowin et al. 2001, Norgauer et al. 2002). Measurements of the N-terminal propeptides of type I (PINP) and III (PIIINP) collagens in blood are commonly used as markers of collagen formation. The concentration of these propeptides reflects the synthesis rate of type I and III collagens. During wound healing, 
types I and III collagens which are produced and deposited by fibroblasts increase the tensile strength of the wound (Mutsaers et al. 1997). It was reported that scar fibroblast selectively increases the biosynthesis of type I collagen, this abnormal metabolism results in the deposition of collagen in scar and alters the steady-state ratio of collagen type I/III in the process of wound healing (Zhang et al. 1995, Niessen et al. 1999). It has been shown by animal experiments that exposure to hyperbaric oxygen increases the expression of type I collagen in healing of tendon laceration (Ishii et al. 1999).

The main pathological condition in the patients with impaired wound healing is diabetes mellitus. In diabetic patients, high blood glucose hinders proliferation of cells and decreases collagen production in foot ulcers that may result in amputation of the extremities (Hehenberger et al. 1998). Hyperbaric oxygen (HBO) therapy has been widely used to treat chronic wounds associated with pathological conditions compromising blood supply and tissue oxygenation (Abidia et al. 2003). Repeated (20-40) exposures of HBO have been shown to exert beneficial effects on glucose metabolism in diabetic patients (Kakhnovski et al. 1982) and to improve the healing in diabetic foot ulcers (Faglia et al. 1996, Kalani et al. 2002).

NO, a versatile signal molecule, is the most potent endogenous vasodilator that regulates many processes including collagen synthesis and matrix remodeling. Kuboki et al. (2000) found that diabetic patients have significantly lower circulating NO levels because the stimulatory action of insulin on NO synthesis is absent. Nitric oxide synthase (NOS), the enzyme that uses L-arginine and molecular oxygen as substrates for the production of NO and L-citrulline, is the key enzyme for the regulation of NO availability. Asymmetric dimethylarginine (ADMA) is an endogenous inhibitor of NOS, and is derived from the catabolism of proteins containing methylated arginine residues. Increased oxidative stress has been shown to lead to increased levels of ADMA (Baylis 2006). In diabetic patients, increased levels of ADMA have been reported (Abbasi et al 2001), but its possible involvement in the wound healing has not been investigated.

In this study, attempts were made to determine the changes in plasma PINP and PIIINP, total nitrite/nitrate (NOx) and ADMA levels; and to evaluate their relation to wound healing during the HBO treatment of foot ulcers in diabetic patients.

\section{Subjects and methods}

\section{Subjects}

Eighteen patients (13 men, 5 women) with diabetic foot ulcers who received hyperbaric oxygen therapy were included in the study. The procedures were in accordance with the revised form of the Helsinki Declaration 2004 and all participants signed an informed consent form. The study protocol was approved by the local ethical committee. Patients were followed by the same physician responsible from diabetic control, wound care and antibiotic therapy according to the clinical and laboratory findings, and were given a diet depending on their metabolic needs without vitamin supplementation. No significant difference occurred in the glucose and $\mathrm{HBA}_{1 \mathrm{c}}$ levels of patients during the experimental period. Fasting blood glucose levels ranged between 100-300 $\mathrm{mg} / \mathrm{dl}$ and blood $\mathrm{HbA}_{1 \mathrm{c}}$ concentrations were between 6.3$12.6 \%$ (for other characteristics of patients see Table 1).

Table 1. Clinical and laboratory characteristics of the patients before and after hyperbaric oxygen treatment (HBOT).

\begin{tabular}{lcc} 
& Before & After \\
& HBOT & HBOT \\
\hline Men/Women & $13 / 5$ & \\
Age & $61 \pm 8.26$ & \\
BMI $\left(\mathrm{kg} / \mathrm{m}^{2}\right)$ & $26.1 \pm 3.73$ & \\
DM duration $($ years $)$ & $18.6 \pm 10.0$ & \\
PINP $(\mu \mathrm{g} / \mathrm{l})$ & $32.6 \pm 29.4$ & $44.3 \pm 33.4^{*}$ \\
PIIINP $(\mu \mathrm{g} / \mathrm{l})$ & $6.97 \pm 3.01$ & $7.92 \pm 2.49^{*}$ \\
ADMA $(\mu \mathrm{mol} / \mathrm{l})$ & $1.33 \pm 0.5$ & $1.20 \pm 0.49$ \\
NOx $(\mu \mathrm{mol} / \mathrm{l})$ & $76.6 \pm 41.5$ & $83.7 \pm 38.9$ \\
\hline
\end{tabular}

*p $<0.05$ compared to baseline values. DM - diabetes mellitus.

\section{HBO treatment}

Along with the standard wound care and medical therapy, all subjects underwent HBO treatment according to a routine protocol for diabetic foot ulcers with healing problems, determined by the European Committee on Hyperbaric Medicine and also by the Hyperbaric Oxygen Committee of Undersea and Hyperbaric Medicine (Wattel 1998, Feldmeier 2003). HBO treatment was carried out in a multiplace hyperbaric chamber once a day, and six days in a week. The treatment protocol was inhalation of $3 \times 25$ min periods of $100 \%$ oxygen at a pressure of 2.4 ATA, interspersed with 5 min periods of air breathing. 


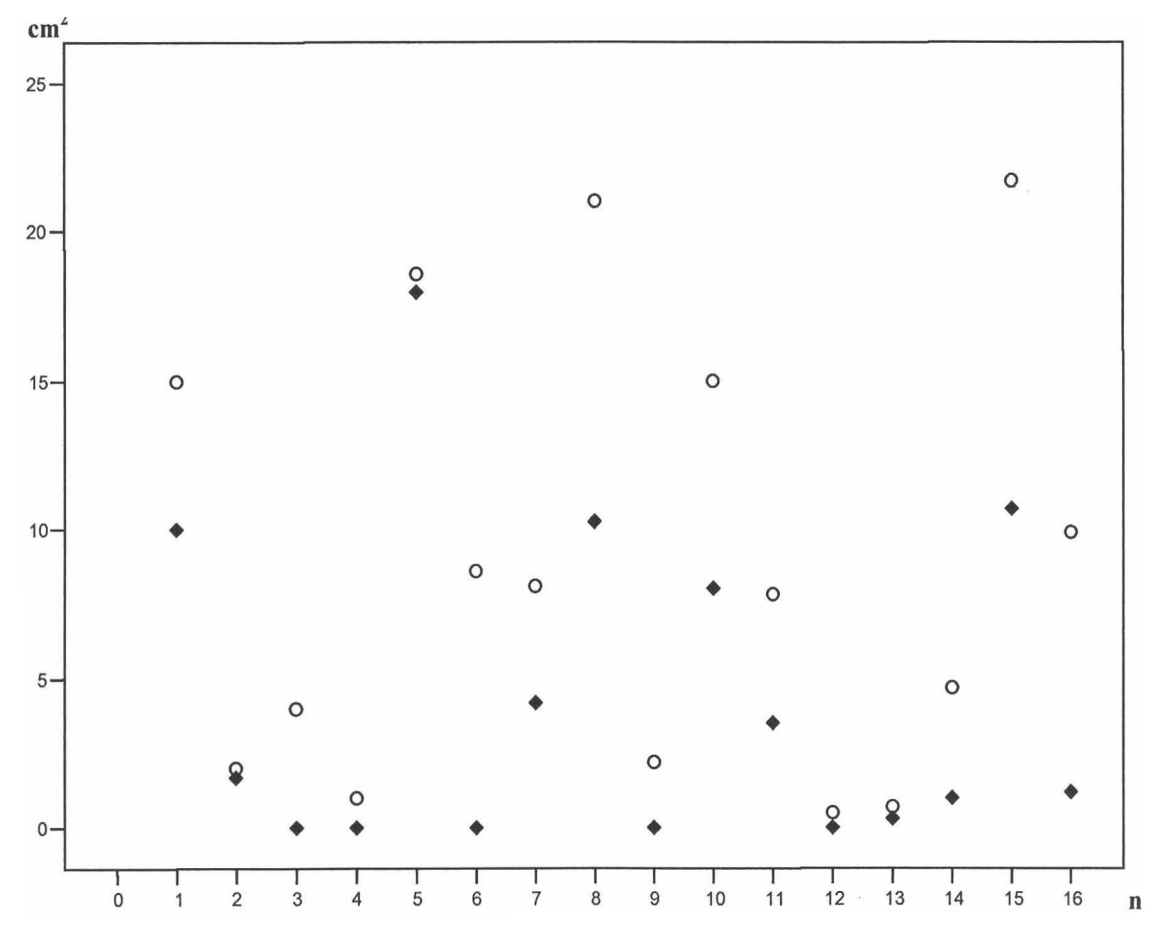

Fig. 1. Wound surface area $\left(\mathrm{cm}^{2}\right)$ as estimated by the digital wound imaging in each patient.

O Before HBOT, $\diamond$ After HBOT

\section{Sample collection and wound size evaluation}

On the day of HBO treatment, the patients were admitted to the clinic between 8.00-11.00 a.m. Venous blood samples $(10 \mathrm{ml})$ were collected from each patient prior to the hyperbaric oxygen therapy in a standard sterile vacuum tube containing EDTA, and immediately centrifuged at $600 \mathrm{~g}$ for $15 \mathrm{~min}$. Aliquots of plasma were stored at $-80{ }^{\circ} \mathrm{C}$ until used for the determinations of PINP, PIIINP, NOx and ADMA. After 25-30 sessions of HBO therapy, varying degrees of clinical healing were observed in the patients, and blood samples were collected for the repetitive measurements.

Clinimetric evaluation of the wounds was based on digital wound imaging, and the changes in the wound surface area were calculated with planimetric measurements using a constant reference (Kantor and Margolis 1998, Quan et al. 2007).

\section{Analytical procedures}

PINP and PIIINP levels were measured using commercially available competitive radioimmunoassay kit (Orion Diagnostica UniQ, Espoo, Finland). Minimum detectable doses were $2 \mu \mathrm{g} / 1$ and $0.3 \mu \mathrm{g} / 1$, the interassay CVs were $<9.8 \%$ and $<6.5 \%$; and intraassay CVs $<9.8 \%$ and $<3.0 \%$, respectively. Results were expressed as $\mu \mathrm{g} / 1$.

NOx (nitrite and nitrate) analyses were carried out using total nitric oxide assay kit (R\&D System Europe, Abingdon, UK). Minimum detectable dose ranges from 0.09 to $0.78 \mathrm{mmol} / \mathrm{l}$, the interassay $\mathrm{CV}$ was $<4.6 \%$, and intraassay $\mathrm{CV}<2.5 \%$. Results were expressed as $\mu \mathrm{mol} / 1$.

ADMA levels were measured in samples by a commercial ELISA kit (DLD Diagnostika, Hamburg, Germany). The reference ranges were between 0.4 and $0.75 \mathrm{mmol} / \mathrm{l}$; the intraassay and interassay coefficients of variation were $<8 \%$ and $<10 \%$, respectively. Results were expressed as $\mu \mathrm{mol} / 1$.

\section{Statistics}

Results were expressed as means \pm SD. The significance of differences between groups was assessed using Wilcoxon test. $\mathrm{P}<0.05$ values were regarded as significant. Correlations were estimated using the Spearman test. All analyses were performed with the Statistical Package for the Social Sciences (12.0 software version, SPSS Inc, Chicago, IL, USA).

\section{Results}

Biochemical data obtained in patients before and after 25-30 sessions of HBO treatment are shown in Table 1.

PINP and PIIINP levels were increased in 14 patients when compared with the baseline values, the increments being statistically significant $(p<0.05)$. Eleven patients with increased levels of procollagen peptides had $50 \%$ or more decreased wound surface area. Wounds 
were evaluated by measuring the surface area twice on digital wound imaging, prior to the therapy and after 25-30 successive HBO treatments; and the degree of healing was expressed as the percentage of healed area. Two subjects were excluded from this evaluation due to the absence of the digital imaging data. Of 16 subjects, two had minimal improvements on wound surface (with $15 \%$ or less healing), whereas the remaining patients gave a favorable response as follows: in 7 patients, the degree of wound healing $78 \%$ or higher; and 7 patients with the healing percentages 33 to 57 (Figure 1).

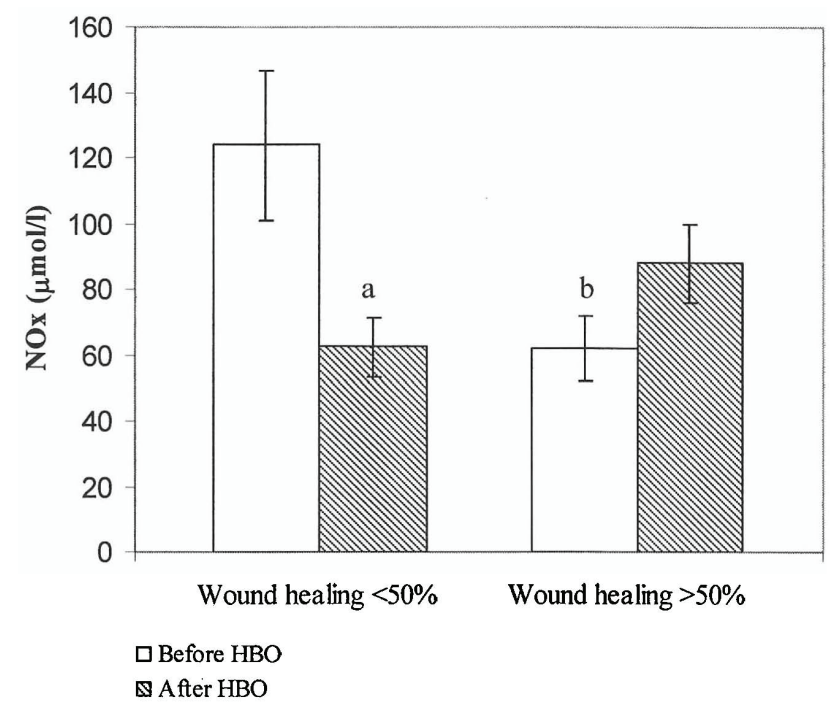

Fig. 2. Plasma NOx levels before and after 25-30 sessions of $\mathrm{HBO}$ therapy in diabetic patients who were classified according to the degree of wound area change. ${ }^{a} p<0.05$ in comparison to basal levels (before HBO). ${ }^{b} p<0.05$ in comparison to the patients with less than $50 \%$ healing (before $\mathrm{HBO}$ ).

When the patients were classified according to the degree of healing $(<50 \%$ or $>50 \%)$, the baseline NOx levels differed significantly between the two groups ( $p<0.05$; Fig. 2). In addition, elevated NOx levels were seen in patients whose wounds were healed by $50 \%$ or more following HBO therapy. On the other hand, the patients who showed minor improvements (less than $50 \%$ of healing) had decreased levels of NOx after the exposure to $\mathrm{HBO}$. The individual variations in $\mathrm{NOx}$ levels are shown in Figure 3.

Baseline plasma ADMA was lower in patients (1.25 $\pm 0.5 \mu \mathrm{mol} / \mathrm{l})$ who responded favorably (50\% or more healing) to HBO treatment when compared to that $(1.59 \pm 0.56 \mu \mathrm{mol} / \mathrm{l})$ in the other patients who poorly responded to the treatment (below $50 \%$ ). In 7 patients with $78 \%$ or more healing, plasma ADMA was lowest before the therapy $(1.09 \pm 0.55 \mu \mathrm{mol} / \mathrm{l})$. No significant difference was observed between ADMA levels before and after HBO treatment when the patients were classified according to the degree of healing (data not shown).

The duration of diabetes was negatively correlated with wound healing $(\mathrm{r}=-0.498, \mathrm{p}<0.05)$; but after adjusting for $\mathrm{HbA}_{1 \mathrm{c}}$ by two-tailed partial correlation, this negative correlation no longer existed.

No correlation was detected between PINP and PIIINP levels. Neither ADMA nor NOx levels were correlated with the procollagen peptides. There was no significant relation between these two parameters either before or after the 25-30 sessions of HBOT. The relation between the changes in wound area and in the abovementioned biochemical parameters was examined by the categorical analysis (the increment in the measured parameter versus $>50 \%$ of healed area), the changes in NOx levels were found to be significantly associated with the degree of healing $(\mathrm{p}=0.001)$.

\section{Discussion}

The improvement of wound healing is directly associated with the periwound-tissue oxygen tension (Smith et al. 1996). The beneficial effects of hyperbaric oxygen on the healing of foot ulcers and glucose metabolism have been documented in patients with diabetes mellitus (Kakhnowski et al. 1982, Kalani et al. 2002, Abidia et al. 2003, Kessler et al. 2003). In the present study, type I and III procollagen N-peptides were significantly increased in sera following 25-30 sessions of HBO. This finding suggests that successive exposures to HBO increase collagen synthesis as the rate of healing is accelerated. It is well known that molecular oxygen is essential for collagen synthesis, especially for the posttranslational hydroxylation of proline and lysine in procollagen during the process of collagen maturation. However, the concentrations of PINP and PIIINP measured in this study reflect the rate of synthesis rather than the maturation of procollagen fibers. It has previously been shown that HBO exposure may activate secretion of growth factors through the generation of reactive oxygen species (Tandara and Mustoe 2004, Shyu et al. 2008). After HBO therapy, an increase in transforming growth factor (TGF)- $\beta$ production has been observed (Kang et al. 2004). Together with the previous reports, our findings support a promoting role for oxygen on collagen synthesis rather than maturation process. 


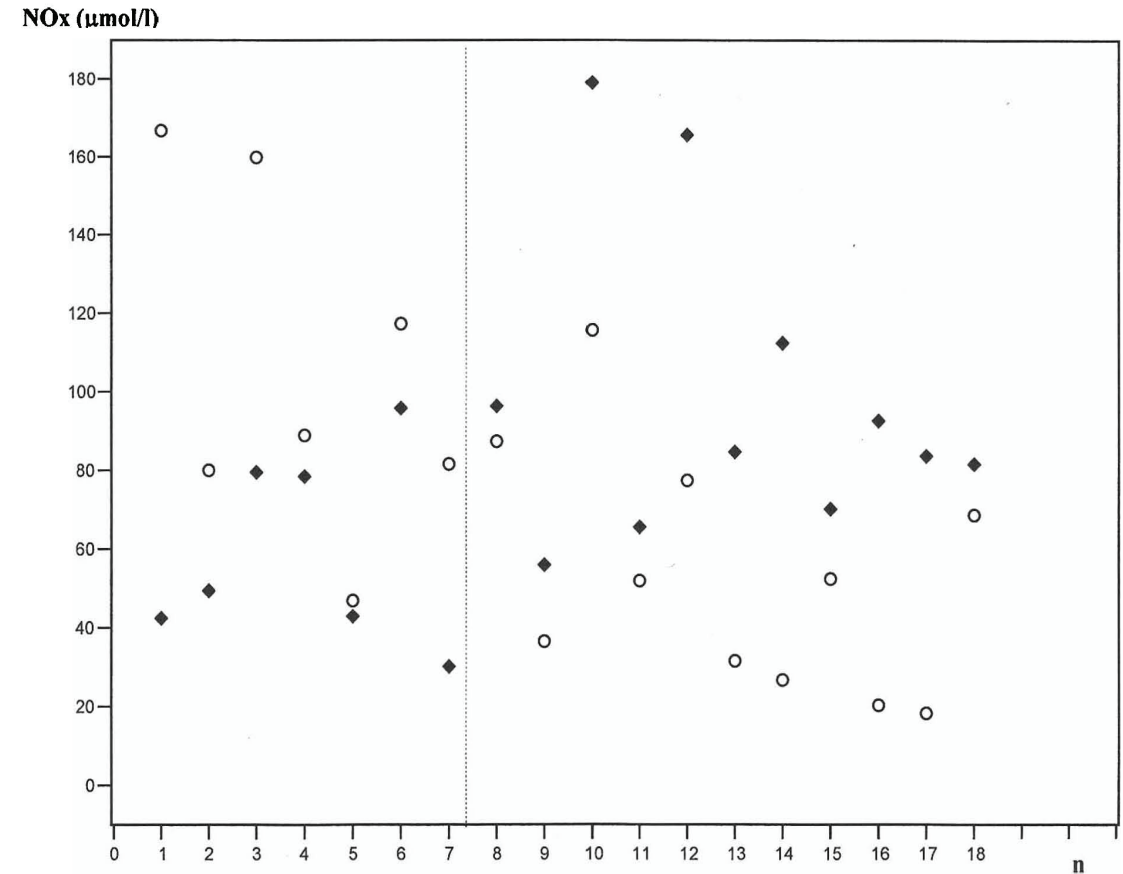

Fig. 3. Plasma NOx levels in diabetic patients before and after HBO therapy. Data right to the dotted line show increased NOx levels following HBO (11 patients). Patients with decreased NOx levels are placed left to the dotted line. $O$ Before HBOT, $\diamond$ After HBOT
It has previously been shown that deposition of collagen types in wound area differs with regard to the stages of healing. In the earliest stage, excessive type III collagen is seen but later type I collagen predominates (Mutsaers et al. 1997). Since the degree of wound healing was not similar in our subjects, a significant association between PINP and PIIINP could not be detected.

Ongoing experimental and clinical wound healing studies have presented NO as a critical mediator of tissue repair (Schwentker and Billiar 2003). NO levels were found to be significantly increased in wound fluid (Boykin and Baylis 2007), while it remained unaltered in plasma after a short-term HBO treatment (Chen et al. 2007). Reports related to the effect of hyperbaric oxygen on NO production in normal tissues are conflicting (Thom et al. 2003, Elayan et al. 2000, Akgul et al. 2007). In our study, the basal levels of NOx were significantly higher in patients who exhibited a lesser degree of wound healing in response to the therapy. In this group, NOx levels were significantly decreased after the HBO exposure. In contrast, the patients who had a good response to HBO therapy had a relatively low baseline NOx, which was followed by a slight elevation after HBO. In a recent study, an improved wound healing due to increased nitric oxide generation has been demonstrated after HBO (Gallagher et al. 2007). These observations led us to suggest that there is an optimum NO level for its contribution the healing process.

In our study, ADMA levels were slightly higher than those in healthy subjects, which are estimated to be $\sim 1 \mu \mathrm{mol} / 1$ (Cooke 2000). This elevation may be related to oxidative stress owing to diabetes. Some studies have shown an elevation, while others demonstrated a decrease in ADMA levels of diabetic patients (Abbasi et al. 2001, Paiva et al. 2003), but the role of this metabolite on wound healing has not been investigated. In this study, we observed a lesser degree of healing in patients with relatively high baseline ADMA levels, while baseline ADMA levels were lowest in 7 patients who favorably responded to HBO treatment with $78 \%$ or more healing. Since our study had a limited sample size, further studies should be carried out in order to claim that determination of plasma ADMA levels may be useful to predict the prognosis of healing in diabetic patients. Supplementation of L-arginine, which is a common precursor for NO and polyamine synthesis, has enhanced wound healing in experimental animals (Shi et al. 2003). Therefore, the ratio of arginine to ADMA appears to be more important than ADMA alone for the repairing process.

In conclusion, HBO treatment results in significant increases in both type I and III collagen synthesis. A slight increase observed in NO levels during this process may contribute to the wound healing. Further studies are needed to establish whether the effect of hyperbaric oxygen therapy on healing of diabetic foot lesions can be enhanced by L-arginine supplementation in humans. 


\section{Conflict of Interest}

There is no conflict of interest.

\section{Acknowledgements}

This work was supported by the Research Fund of Istanbul University. Projects: 247/23082004 and UDP$1774 / 23112007$.

\section{References}

ABBASI F, ASAGMI T, COOKE JP, LAMENDOLA C, MCLAUGHLIN T, REAVEN GM, STUEHLINGER M, TSAO PS: Plasma concentrations of asymmetric dimethyl arginine are increased in patients with type 2 diabetes mellitus. Am J Cardiol 88: 1201-1203, 2001.

ABIDIA A, LADEN G, KUHAN G, JOHNSON BF, WILKINSON AR, RENWICK PM, MASSON EA, MCCOLLUM PT: The role of hyperbaric oxygen therapy in ischaemic diabetic lower extremity ulcers: a double-blind randomised-controlled trial. Eur J Vasc Endovasc Surg 25: 513-518, 2003.

AKGUL EO, CAKIR E, OZCAN O, YAMAN H, KURT YG, OTER S, KORKMAZ A, BILGI C, ERBIL MK: Pressure-related increase of asymmetric dimethylarginine caused by hyperbaric oxygen in the rat brain: a possible neuroprotective mechanism. Neurochem Res 32: 1586-1591, 2007.

BAYLIS C: Arginine, arginine analogs and nitric oxide production in chronic kidney disease. Nat Clin Pract Nephrol 2: 209-220, 2006.

BOYKIN JV Jr, BAYLIS C: Hyperbaric oxygen therapy mediates increased nitric oxide production associated with wound healing: a preliminary study. Adv Skin Wound Care 20: 382-388, 2007.

CHEN SJ, YU CT, CHENG YL, YU SY, LO HC: Effects of hyperbaric oxygen therapy on circulating interleukin-8, nitric oxide, and insulin-like growth factors in patients with type 2 diabetes mellitus. Clin Biochem 40: 30-36, 2007.

COOKE JP: Does ADMA cause endothelial dysfunction? Arterioscler Thromb Vasc Biol 20: 2032-2037, 2000.

COWIN AJ, HATZIRODOS N, HOLDING CA, DUNAISKI V, HARRIES RH, RAYNER TE, FITRIDGE R, COOTER RD, SCHULTZ GS, BELFORD DA: Effect of healing on the expression of transforming growth factor beta(s) and their receptors in chronic venous leg ulcers. J Invest Dermatol 117: 1282-1289, 2001.

ELAYAN IM, AXLEY MJ, PRASAD PV, AHLERS ST, AUKER CR: Effect of hyperbaric oxygen treatment on nitric oxide and oxygen free radicals in rat brain. $J$ Neurophysiol 83: 2022-2029, 2000.

FAGLIA E, FAVALES F, ALDEGHI A, CALIA P, QUARANTIELLO A, ORIANI G, MICHAEL M, CAMPAGNOLI P, MORABITO A: Adjunctive systemic hyperbaric oxygen therapy in treatment of severe prevalently ischemic diabetic foot ulcer. A randomized study. Diabetes Care 19: 1338-1343, 1996.

FELDMEIER JJ: Hyperbaric Oxygen: Indications and Results. The Hyperbaric Oxygen Therapy Committee Report. Undersea and Hyperbaric Medical Society, Maryland, USA, 2003.

GALlAGHER KA, LIU ZJ, XIAO M, CHEN H, GOLDSTEIN LJ, BUERK DG, NEDEAU A, THOM SR, VELAZQUEZ OC: Diabetic impairments in NO-mediated endothelial progenitor cell mobilization and homing are reversed by hyperoxia and SDF-1 alpha. J Clin Invest 117: 1249-1259, 2007.

HEHENBERGER K, HEILBORN JD, BRISMAR K, HANSSON A: Inhibited proliferation of fibroblasts derived from chronic diabetic wounds and normal dermal fibroblasts treated with high glucose is associated with increased formation of L-lactate. Wound Repair Regen 6: 135-141, 1998.

HEHENBERGER K, KRATZ G, HANSSON A, BRISMAR K: Fibroblasts derived from human chronic diabetic wounds have a decreased proliferation rate, which is recovered by the addition of heparin. J Dermatol Sci 16: 144-151, 1998.

ISHII Y, MIYANAGA Y, SHIMOJO H, USHIDA T, TATEISHI T: Effects of hyperbaric oxygen on procollagen messenger RNA levels and collagen synthesis in the healing of rat tendon laceration. Tissue Eng 5: 279-286, 1999.

KAKHNOVSKI IM, FOKINA TS, MAKSIMOVA IE, KAKHNOVSKAIA VB: Effect of insulin therapy and hyperbaric oxygenation on the enzyme activity of tissue metabolism in diabetes mellitus. Probl Endokrinol 28: 11-17, 1982. 
KALANI M, JORNESKOG G, NADERI N, LIND F, BRISMAR K: Hyperbaric oxygen (HBO) therapy in treatment of diabetic foot ulcers. Long-term follow-up. J Diabetes Complications 16: 153-158, 2002.

KANG TS, GORTI GK, QUAN SY, HO M, KOCH RJ: Effect of hyperbaric oxygen on the growth factor profile of fibroblasts. Arch Facial Plast Surg 6: 31-35, 2004.

KANTOR J, MARGOLIS DJ: Efficacy and prognostic value of simple wound measurements. Arch Dermatol 134: 1571-1574, 1998.

KESSLER L, BILBAULT P, ORTEGA F, GRASSO C, PASSEMARD R, STEPHAN D, PINGET M, SCHNEIDER F: Hyperbaric oxygenation accelerates the healing rate of nonischemic chronic diabetic foot ulcers: a prospective randomized study. Diabetes Care 26: 2378-2382, 2003.

KUBOKI K, JIANG ZY, TAKAHARA N, HA SW, IGARASHI M, YAMAUCHI T, FEENER EP, HERBERT TP, RHODES CJ, KING GL: Regulation of endothelial constitutive nitric oxide synthase gene expression in endothelial cells and in vivo: a specific vascular action of insulin. Circulation 101: 676-681, 2000.

MUTSAERS SE, BISHOP JE, MCGROUTHER G, LAURENT GJ: Mechanisms of tissue repair: from wound healing to fibrosis. Int J Biochem Cell Biol 29: 5-17, 1997.

NIESSEN FB, SPAUWEN PH, SCHALKWIJK J, KON M: On the nature of hypertrophic scars and keloids: a review. Plast Reconstr Surg 104: 1435-1458, 1999.

NORGAUER J, HILDENBRAND T, IDZKO M, PANTHER E, BANDEMIR E, HARTMANN M, VANSCHEIDT W, HEROUY Y: Elevated expression of extracellular matrix metalloproteinase inducer (CD147) and membranetype matrix metalloproteinases in venous leg ulcers. Br J Dermatol 147: 1180-1186, 2002.

PÄIVÄ H, LEHTIMÄKI T, LAAKSO J, RUOKONEN I, RANTALAIHO V, WIRTA O, PASTERNACK A, LAAKSONEN R: Plasma concentrations of asymmetric-dimethylarginine in type 2 diabetes associate with glycemic control and glomerular filtration rate but not with risk factors of vasculopathy. Metabolism 52: 303307, 2003.

QUAN SY, LAZARUS GS, KOHLI AR, KAPOOR R, MARGOLIS DJ: Digital imaging of wounds: are measurements reproducible among observers? Int J Low Extrem Wounds 6: 245-248, 2007.

SCHWENTKER A, BILLIAR TR: Nitric oxide and wound repair. Surg Clin North Am 83: 521-530, 2003.

SHEIKH AY, GIBSON JJ, ROLLINS MD, HOPF HW, HUSSAIN Z, HUNT TK: Effect of hyperoxia on vascular endothelial growth factor levels in a wound model. Arch Surg 135: 1293-1297, 2000.

SHI HP, MOST D, EFRON DT, WITTE MB, BARBUL A: Supplemental L-arginine enhances wound healing in diabetic rats. Wound Repair Regen 11: 198-203, 2003.

SHYU KG, HUNG HF, WANG BW, CHANG H: Hyperbaric oxygen induces placental growth factor expression in bone marrow-derived mesenchymal stem cells. Life Sci 83: 65-73, 2008.

SMITH BM, DESVIGNE LD, SLADE JB, DOOLEY JW, WARREN DC: Transcutaneous oxygen measurements predict healing of leg wounds with hyperbaric therapy. Wound Repair Regen 4: 224-229, 1996.

TANDARA AA, MUSTOE TA: Oxygen in wound healing -more than a nutrient. World J Surg 28: 294-300, 2004.

THOM SR, FISHER D, ZHANG J, BHOPALE VM, OHNISHI ST, KOTAKE Y, OHNISHI T, BUERK DG: Stimulation of perivascular nitric oxide synthesis by oxygen. Am J Physiol 284: H1230-H1239, 2003.

WATTEL F: European Committee Consensus Conference on Hyperbaric Oxygen in the Treatment of Foot Lesions in Diabetic Patients. ECHM. Glaxo-Welcome, France, 1998.

ZHANG K, GARNER W, COHEN L, RODRIGUEZ J, PHAN S: Increased types I and III collagen and transforming growth factor-beta 1 mRNA and protein in hypertrophic burn scar. J Invest Dermatol 104: 750-754, 1995. 